\title{
Detection of EBV-encoded Small RNA from Diffuse Large B-cell Lymphoma Patients by RT-PCR Method
}

\author{
Tae Hyun Yoo ${ }^{1}$, Min Ho Lee ${ }^{1}$, Min Park ${ }^{1}$, Jaewang Lee ${ }^{2}$, Hyun Jun Woo ${ }^{1}$, Hyun Woo Kim ${ }^{1}$, \\ Ji Yeong Yang ${ }^{1}$, Hye Jin Kwon ${ }^{1}$, Min Ji Yeon ${ }^{1}$ and Jong-Bae Kim ${ }^{1, \uparrow}$ \\ ${ }^{I}$ Department of Biomedical Laboratory Science, College of Health Sciences, Yonsei University, \\ Wonju, Gangwon-do 26493, Korea \\ ${ }^{2}$ Department of Hospital Pathology, St. Vincent's Hospital, The Catholic University of Korea, Seoul 16247, Korea
}

\begin{abstract}
Epstein-Barr virus (EBV) has a pathogenic role in several lymphomas including diffuse large B-cell lymphoma (DLBCL). In this study, we detected EBV from formalin-fixed paraffin embedded (FFPE) tissues of DLBCL patients by RT-PCR and compared the sensitivity of the RT-PCR method to in situ hybridization (ISH) method. The RNA was extracted from 91 FFPE samples with DLBCL and amplified with primers targeting EBV-encoded small RNA (EBER) by RT-PCR. When using the RT-PCR method, 13 of 91 patients (14.3\%) were positive and among these 13 cases, 7 cases $(7.7 \%)$ were from $>50$-year-old patients that is classified as EBV positive DLBCL of the elderly. In previous results using ISH method, 3 of 91 patients $(3.3 \%)$ were positive and 2 case $(2.4 \%)$ were older than 50 -year-old. These results indicate that RT-PCR method used in this study shows a higher sensitivity than ISH method. The ratio of male versus female among the EBV positive samples was 1.2:1 with the ratio of male higher. If RT-PCR method having high sensitivity is used simultaneously as well as the ISH method providing the information of the EBV positive cellular location, it is expected that EBV will be more accurately detected.
\end{abstract}

Key Words: EBV, EBER, RT-PCR, DLBCL

\section{INTRODUCTION}

EBV is a human herpesvirus-4 (HHV-4) which possesses $172 \mathrm{kbp}$ long double stranded DNA, and it was first discovered from human cancer cells in 1963 (Epstein, 1994). More than $90 \%$ of adult human population worldwide is infected with EBV. EBV is mainly transmitted through saliva, and primarily targets $B$ lymphocytes and laryngopharyngeal epithelial cells (Niedobitek and Young, 1994; Gratama and

\footnotetext{
* Received: September 17, 2015 / Revised: October 5, 2015

Accepted: October 6, 2015

${ }^{\dagger}$ Corresponding author: Jong-Bae Kim. Department of Biomedical Laboratory Science, College of Health Sciences, Yonsei University, Wonju 26493, Korea.

Tel: +82-33-760-2423, Fax: +82-33-760-2561

e-mail: kimjb70@yonsei.ac.kr

(c) The Korean Society for Biomedical Laboratory Sciences. All rights reserved.
}

Ernberg, 1995). EBV infects and proliferates in laryngopharynx by lytic replication, then spreads to the surrounding epithelial cells and B lymphocytes. Infected B lymphocytes move to other organs or lymphatic tissues via blood circulation and transmit the virus to other epithelial cells and $\mathrm{B}$ lymphocytes (Niedobitek and Young, 1994; Gratama and Ernberg, 1995). EBV in B lymphocytes normally maintains the latent form of infection and expresses a limited number of genes which induce immortalization of the host cell (Niedobitek and Young, 1994; Gratama and Ernberg, 1995). The genes expressed during the latent infection include six types of EBV nuclear antigens (EBNA-1, -2, -3A, -3B, $-3 \mathrm{C}$, and -LP), three EBV latent membrane proteins (LMP1, LMP2A, and LMP2B), two EBV encoded small RNAs (EBER1, and EBER2) and transcripts from Bam $\mathrm{HI}-\mathrm{A}$ region (Gratama and Ernberg, 1995; Anagnostopoulos and Hummel, 
1996).

EBV infection is mostly asymptomatic. However, initial infection of EBV during adolescent period occasionally induces infectious mononucleosis, and it was also reported that EBV infection contributes to the development of Hodgkin's lymphoma, Burkitt's lymphoma, nasopharyngeal carcinoma, gastric carcinoma and lymphoproliferative disorders in HIV or immune suppressed patients (Raab-Traub, 1992; Knipe and Howley, 1996). The genes expressed during the latent state of infection are involved in the EBVassociated development of cancer, and especially in vitro, LMP1 and EBNA2 are known to play the most important role in the immortalization of B lymphocytes (Knipe and Howley, 1996).

EBER is the most abundantly expressed gene during the latent state of EBV infection, but the transcript is not translated to a protein. There are two types of EBER genes (EBER1 and EBER2). EBER1 and EBER2 genes are 162 and 172 nucleotides in lenght and they are transcribed by host RNA polymerase III (Rosa et al., 1981). Although, the precise mechanism and the role of EBER in immortalization of the host cell is unclear, B lymphocytes expressing EBER show resistance to apoptosis (Nanbo et al., 2002), and recent reports discovered that EBER binds to intracellular proteins and it is secreted to the outside of the cells thereby inducing secretion of various cytokines associated with inflammation (Kitagawa et al., 2000; Iwakiri et al., 2003; Yang et al., 2004; Iwakiri et al., 2005). In particular, EBER is being used as a diagnostic target for EBV infection because the gene is expressed considerably a lot in the latent infection (Chang et al., 1992). Therefore, in-situ hybridization (ISH) targeting EBER gene in the formalin fixed paraffin embedded (FFPE) tissue is currently used as a gold standard method for detection of EBV infection (Chang et al., 1992). The strength of ISH is the method shows not only the presence of EBV infection but also provides the location of EBV infected lesion. However, sensitivity of the ISH is considered to be lower than PCR method (Qi et al., 2013).

Diffuse large B cell lymphoma (DLBCL) is one of the most common type of lymphomas which accounts for 30 $40 \%$ of non-Hodgkin's lymphomas (The Non-Hodgikin's Lymphoma Classification Project, 1997). The average age of the DLBCL patients is 70 years and the progression of the disease is considered to be fast (Vinay et al., 2010; Smith et al., 2011). In particular, it has been reported that EBVpositive DLBCL of the elderly showed poor prognosis which includes less responsiveness to therapies and shorter survival rate than that of EBV-negative DLBCL (Oyama et al., 2007; Park et al., 2007). In this study, we used RT-PCR method and targeted EBER to detect EBV infection from the FFPE samples of the DLBCL patients.

\section{MATERIALS AND METHODS}

\section{Collection of FFPE samples and RNA extraction}

A total of 91 FFPE tissues diagnosed with DLBCL from January 2002 to December 2012 were collected at St. Vincent Hospital. This study was approved by St. Vincent Hospital Institutional Review Board (IRB number VC14SISI0127). The FFPE tissues were sectioned $(10 \mu \mathrm{m})$ and placed in sterile $1.5 \mathrm{ml}$ tube. The tissue sections were treated with $1 \mathrm{ml}$ xylene to remove paraffin from the tissues, then xylene was removed by ethanol. Tissue homogenized buffer (75 $\mu$ l), $10 \% \operatorname{SDS}(15 \mu \mathrm{l})$ and proteinase $\mathrm{K}(9 \mu \mathrm{l})$ were added to the tissues and incubated at $55^{\circ} \mathrm{C}$ overnight. The tissues were then treated with $1 \mathrm{ml}$ Trizol and RNA was extract according to the manufacturer's instruction. Briefly, $200 \mu$ l of chloroform was added to Trizol treated samples, vigorously mixed and centrifuged at 13,500 RPM for $15 \mathrm{~min}$. Aqueous phase was moved to a new tube and the equal volume of isopropanol was added to precipitate RNA. The mixture was incubated for $15 \mathrm{~min}$ and then centrifuged at 13,500 RPM for $10 \mathrm{~min}$. Precipitated RNA was washed once with $75 \%$ ethanol in DEPC treated water and completely dried then RNA was finally dissolved in DEPC water.

\section{RT-PCR (Reverse transcriptase - polymerase chain reaction)}

Extracted RNA was quantified by infinite M200PRO (TECAN) and cDNA was synthesized using $2 \mu \mathrm{g}$ of RNA. Ten-fold diluted cDNA was subjected to PCR. Cycling conditions are as follows: denaturation at $95^{\circ} \mathrm{C}$ for $5 \mathrm{~min}$, followed by amplification cycle at $95^{\circ} \mathrm{C}$ for $30 \mathrm{sec}, 50^{\circ} \mathrm{C}$ $30 \mathrm{sec}, 72^{\circ} \mathrm{C} 30 \mathrm{sec}$ for 30 cycles and final extension at 

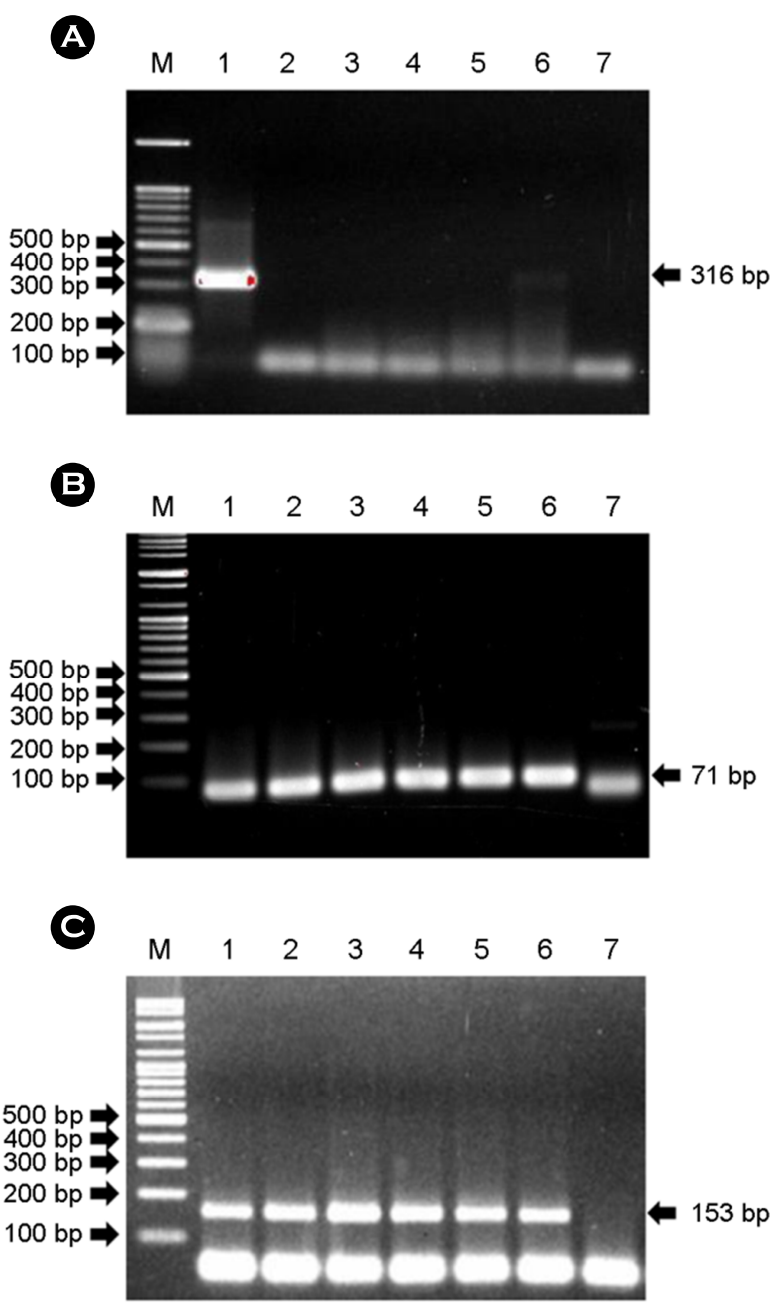

Fig. 1. GAPDH RT-PCR with formalin fixed paraffin embedded (FFPE) tissues from diffuse large B cell lymphoma (DLBCL) patient. (A) Samples from FFPE tissues are not amplified at 316 $\mathrm{bp}$, because the RNA from FFPE may be too fragmented to be amplified. (B) Samples from FFPE tissues are amplified at $71 \mathrm{bp}$, but RT-PCR product can be confused with primer dimer. (C) Samples from FFPE tissues are amplified at $153 \mathrm{bp}$, and RT-PCR product is not confused with primer dimmer. Lane M: size marker, lane 1: RNA from human cell line, lanes 2 6: FFPE samples, lane 7: DW.

$72{ }^{\circ} \mathrm{C} 7 \mathrm{~min}$. Amplified product was separated on $2 \%$ agarose gel, stained with ethidium bromide $(0.5 \mu \mathrm{g} / \mathrm{ml})$ for $10 \mathrm{~min}$, and the image was taken by GelDoc Image Analyzer (Biorad, Hercules, USA). The size of the product was compared to 100 bp DNA ladder (Fermentas, Burlington, Canada). The sequences of the primers are as follows: GAT CCA AAC TTT AGT TTT AG (EBER1 forward), GCG AAC CGT AAC TCT ATA C (EBER1 reverse), CCA CAT GGC TCA
GAC ACC AT (GAPDH 71 bp forward), ACC AGG CGC CCA ATA CG (GAPDH 71 bp reverse), CCA CAT GGC TCA GAC ACC AT (GAPDH 153 bp forward), GTA AAC CAT GTA GTT GAG GTC (GAPDH 153 bp reverse), TAT GAC AAC AGC CTC AAG AT (GAPDH 316 bp forward), and AGG TCC ACC ACT GAC ACG TT (GAPDH 316 bp reverse). The primers for EBER1 were designed in our study group and specificity of the primers was confirmed by sequencing of the amplicon in our recent report (Lee et al., 2015). The primer sequences for GAPDH were obtained from previous reports (Petry et al., 2006; Kashofer et al., 2013).

\section{RESULTS AND DISCUSSIONS}

\section{Design of PCR primers appropriate to amplify the RNA from FFPE samples}

FFPE tissues are generally fixed with formalin that subsequently results in the fragmentation of RNA in the tissue. Therefore, we designed three different primers with different product length $(71,153$ and $316 \mathrm{bp})$ to select the suitable product length for PCR. In the results, the amplicon was hardly detectable with the primer designed to produce 316 bp PCR products (Fig. 1A). We presumed that this was because of the fragmentation of RNA in FFPE samples. According to the previous report, RNA was fragmented to less than $361 \mathrm{bp}$ in FFPE samples that was concordant with our result (Bonin et al., 2003). In contrast, the amplicon was detectable with the primer designed to produce $71 \mathrm{bp}$ product, although the product was overlapped the primer dimers (Fig. 1B). The primer with 153 bp product size successfully produced amplicon without overlapping primer dimmers (Fig. 1C). Therefore, we designed a primer producing $150 \mathrm{bp}$ product for detection of EBER.

\section{Comparison of RT-PCR method to detect EBER with other methods for diagnosis of DLBCL}

A total of 91 FFPE tissue samples diagnosed with DLBCL were collected and subjected to RT-PCR with the primer we designed to detect EBER. A PCR product of $150 \mathrm{bp}$ was detectable with the primer we designed and 13 of $91(14.3 \%)$ were shown to be positive for EBER (Fig. 


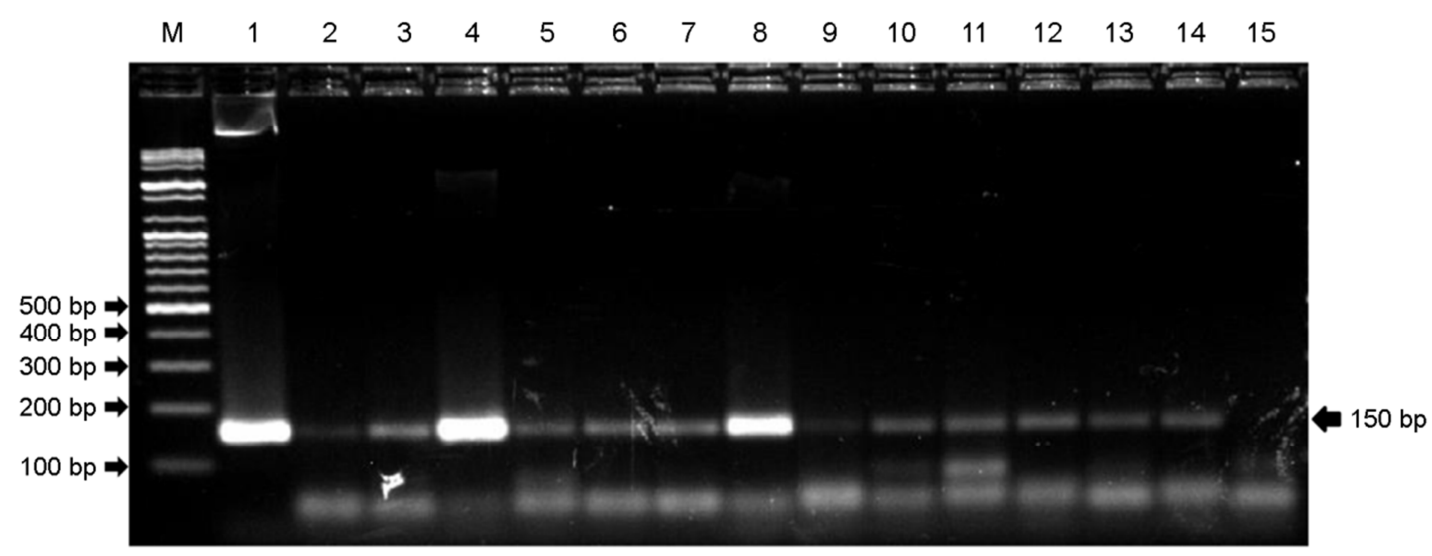

Fig. 2. RT-PCR of Epstein-Barr virus encoded small RNA (EBER) with formalin fixed paraffin embedded (FFPE) tissues from DLBCL patients. Lane M: marker, lane 1: positive control, lanes 2 14: FFPE samples, lane 15: DW.

Table 1. Clinical characteristics of the DLBCL patients

\begin{tabular}{llccc}
\hline \hline & & Total & $\begin{array}{c}\text { Positive } \\
\text { in ISH }\end{array}$ & $\begin{array}{c}\text { Positive in } \\
\text { RT-PCR }\end{array}$ \\
\hline Case No. (\%) & 91 & $3(3.2 \%)$ & $19(20.9 \%)$ \\
\hline Age & $10 \sim 20$ & 1 & & \\
& $21 \sim 30$ & 4 & & \\
& $31 \sim 40$ & 5 & & \\
& $41 \sim 50$ & 16 & 1 & 5 \\
& $51 \sim 60$ & 15 & & 2 \\
& $61 \sim 70$ & 20 & & 3 \\
& $71 \sim 80$ & 26 & 2 & 2 \\
Sex & $81 \sim 90$ & 4 & & 1 \\
& Male & 45 & 2 & 7 \\
Site of & Female & 46 & 1 & 6 \\
biopsy & Lymph node & 45 & 2 & 7 \\
& $*$ Extra-lymph & 46 & 1 & 6 \\
\hline
\end{tabular}

*Extra-lymph node: adrenal, mediastinum, brain, breast, skin, colon, femur, gingiva, ileum, jejunum, kidney, maxillary sinus, nasal cavity, occipital area, ovary, parotid gland, small intestine, stomach, testis, thyroid gland, tongue, tonsil, urinary bladder and uterus.

2). Among the 13 positive cases, seven (7.7\%) cases were older than 50-year-old that are classified as EBV positive DLBCL of the elderly (Table 1). Our previous result by ISH method showed 3 of 91 (3.3\%) cases were EBV positive and 2 cases $(2.4 \%)$ were included in the EBV positive DLBCL of the elderly (Lee et al., 2015). These results indicate that RT-PCR shows the higher positive rate than ISH method. According to the previous reports, the positive rates of EBV positive DLBCL of the elderly by ISH method were below $5 \%$ in Western countries and 8.7 11.4\% in Asia and Latin America (Kuze et al., 2000; Oyama et al., 2007; Park et al., 2007). In this study, however, the positive rate by ISH method was lower and the positive rate by RT-PCR was higher than the previous reports. There are no determined criteria how to report EBV positive based on what percent of the cancer cells is positive for EBER by ISH method (Ok et al., 2013). Therefore, the positive rate of ISH method varied by the criteria applied. On the contrary, the positive rate by RT-PCR is relatively high because RT-PCR method can detect EBER as long as the gene is expressed. Therefore, it is considered that the difference of positive rate between ISH and RT-PCR method in this study is because of the high sensitivity of RT-PCR and abovementioned reason.

Regression of immune function caused by aging and oncogenic property of EBV is considered as the most significant cause of the DLBCL. Also, chromosomal abnormality in DLBCL is less frequent than in other type of cancers because the immune regression and oncogenicity of EBV is sufficient to induce cancer (Montes-Moreno et al., 2012). However, EBV positive DLBCL in young patients has been reported and there were $5 \mathrm{EBV}$ positive cases in their forties in this study (Smith et al., 2010). Among the EBV positive 
DLBCL patients, male and female distributions were 7 and 6 respectively (male $:$ female $=1.2: 1$ ). Therefore, frequency in male was higher than in female that is in accordance with previous studies which also reported the frequency in male is high (male : female = 1.4 : 1) (Gibson and Hsi, 2009; Hoeller et al., 2010; Beltran et al., 2011; Hofscheier et al., 2011).

When DNA was extracted from the 91 tissue samples and subjected to PCR for EBER and EBV DNA polymerase, the positive rate was $35.5 \%$ and $28.5 \%$ respectively (data not shown). The high positive rates in the PCR results with DNA samples are presumably due to the latent infection of EBV. The three cases positive for ISH were concordantly positive for EBER RT-PCR, EBER PCR and EBV DNA polymerase PCR. There were 2 cases that were negative for ISH but positive for EBER RT-PCR, EBER PCR and EBV DNA polymerase PCR and one of the patient was died 2 month post-therapy at the age of 81 and another 43 year-old patient was impossible to track the prognosis.

In this study, we extracted RNA from FFPE tissue samples of DLBCL patients and detected expression of EBER of EBV by using RT-PCR method. Here we found that RTPCR method with the primer we used could more sensitively detect EBV than ISH method which is a gold standard method for EBV detection. In DLBCL patients, it is important to detect whether EBV is infected or not to predict the response to treatment or prognosis. If RT-PCR method is used, EBV can be more sensitively detected than ISH method. Furthermore, RT-PCR method will detect EBV even faster by using specimens before formalin fixation. However, RT-PCR method cannot provide the information about the cellular location of the EBV-positive cells in contrast to the ISH method. Therefore, the use of RT-PCR along with ISH method will be helpful in the detection of EBV infection.

\section{Acknowledgements}

This work was supported by the Graduate School of Yonsei University and the BK 21 plus project, "Fieldoriented Graduate Program for Biomedical and Molecular Diagnostics Professionals", in the Department of Biomedical Laboratory Science, Yonsei University.

\section{Conflict of interest}

There are no conflicts of interest associated with this manuscript.

\section{REFERENCES}

Anagnostopoulos I, Hummel M. Epstein-Barr virus in tumours. Histopathology. 1996. 29: 297-315.

Beltran BE, Castillo JJ, Morales D, de Mendoza FH, Quinones P, Miranda RN, Gallo A, Lopez-Ilasaca M, Butera JN, Sotomayor EM. EBV-positive diffuse large B-cell lymphoma of the elderly: a case series from Peru. Am J Hematol. 2011. 86: 663-667.

Bonin S, Petrera F, Niccolini B, Stanta G. PCR analysis in archival postmortem tissues. Mol Pathol. 2003. 56: 184-186.

Chang KL, Chen YY, Shibata D, Weiss LM. Description of an in situ hybridization methodology for detection of Epstein-Barr virus RNA in paraffin-embedded tissues, with a survey of normal and neoplastic tissues. Diagn Mol Pathol. 1992. 1: 246 -255 .

Epstein A. Thirty years of Epstein-Barr virus. Epstein-Barr virus Report. 1994. 1: 3-4.

Gibson SE, Hsi ED. Epstein-Barr virus-positive B-cell lymphoma of the elderly at a United States tertiary medical center: an uncommon aggressive lymphoma with a nongerminal center B-cell phenotype. Hum Pathol. 2009. 40: 653-661.

Gratama JW, Ernberg I. Molecular epidemiology of Epstein-Barr virus infection. Adv Cancer Res. 1995. 67: 197-255.

Hoeller S, Tzankov A, Pileri SA, Went P, Dirnhofer S. EpsteinBarr virus-positive diffuse large B-cell lymphoma in elderly patients is rare in Western populations. Hum Pathol. 2010. 41: 352-357.

Hofscheier A, Ponciano A, Bonzheim I, Adam P, Lome-Maldonado C, Vela T, Cortes E, Ortiz-Hidalgo C, Fend F, QuintanillaMartinez L. Geographic variation in the prevalence of EpsteinBarr virus-positive diffuse large B-cell lymphoma of the elderly: a comparative analysis of a Mexican and a German population. Mod Pathol. 2011. 24: 1046-1054.

Iwakiri D, Eizuru Y, Tokunaga M, Takada K. Autocrine growth of Epstein-Barr virus-positive gastric carcinoma cells mediated by an Epstein-Barr virus-encoded small RNA. Cancer Res. 2003. 63: 7062-7067.

Iwakiri D, Sheen TS, Chen JY, Huang DP, Takada K. Epstein-Barr virus-encoded small RNA induces insulin-like growth factor 1 and supports growth of nasopharyngeal carcinoma-derived 
cell lines. Oncogene. 2005. 24: 1767-1773.

Kashofer K, Viertler C, Pichler M, Zatloukal K. Quality control of RNA preservation and extraction from paraffin-embedded tissue: implications for RT-PCR and microarray analysis. PLoS One. 2013. 8: e70714.

Kitagawa N, Goto M, Kurozumi K, Maruo S, Fukayama M, Naoe T, Yasukawa M, Hino K, Suzuki T, Todo S, Takada K. Epstein-Barr virus-encoded poly(A)(-) RNA supports Burkitt's lymphoma growth through interleukin-10 induction. EMBO J. 2000. 19: 6742-6750.

Knipe DM, Howley PM. Fields Virology. 1996. 1: 2343-2396. Lippincott Williams \& Wilkins. Philadelphia.

Kuze T, Nakamura N, Hashimoto Y, Sasaki Y, Abe M. The characteristics of Epstein-Barr virus (EBV)-positive diffuse large B-cell lymphoma: comparison between $\operatorname{EBV}(+)$ and $\operatorname{EBV}(-)$ cases in Japanese population. Jpn J Cancer Res. 2000. 91: 1233-1240.

Lee J, Park M, Lee MH, Woo HJ, Kim HW, Yang JY, Eom YB, Kim SH, Yoon C, Kim JB. Development of EBV-encoded small RNA targeted PCR to classify EBV positive diffuse large B-cell lymphoma (DLBCL) of the elderly. Int J Clin Exp Pathol. 2015. 8: 7859-7868.

Montes-Moreno S, Odqvist L, Diaz-Perez JA, Lopez AB, de Villambrosia SG, Mazorra F, Castillo ME, Lopez M, Pajares R, Garcia JF, Mollejo M, Camacho FI, Ruiz-Marcellan C, Adrados M, Ortiz N, Franco R, Ortiz-Hidalgo C, SuarezGauthier A, Young KH, Piris MA. EBV-positive diffuse large B-cell lymphoma of the elderly is an aggressive post-germinal center B-cell neoplasm characterized by prominent nuclear factor- $\kappa$ B activation. Mod Pathol. 2012. 25: 968-982.

Nanbo A, Inoue K, Adachi-Takasawa K, Takada K. Epstein-Barr virus RNA confers resistance to interferon-alpha-induced apoptosis in Burkitt's lymphoma. EMBO J. 2002. 21: 954-965.

Niedobitek G, Young LS. Epstein-Barr virus persistence and virusassociated tumours. Lancet. 1994. 343: 333-335.

Ok CY, Papathomas TG, Medeiros LJ, Young KH. EBV-positive diffuse large B-cell lymphoma of the elderly. Blood. 2013. 122: $328-340$

Oyama T, Yamamoto K, Asano N, Oshiro A, Suzuki R, Kagami Y, Morishima Y, Takeuchi K, Izumo T, Mori S, Ohshima K, Suzumiya J, Nakamura N, Abe M, Ichimura K, Sato Y, Yoshino
T, Naoe T, Shimoyama Y, Kamiya Y, Kinoshita T, Nakamura S. Age-related EBV-associated B-cell lymphoproliferative disorders constitute a distinct clinicopathologic group: a study of 96 patients. Clin Cancer Res. 2007. 13: 5124-5132.

Park S, Lee J, Ko YH, Han A, Jun HJ, Lee SC, Hwang IG, Park YH, Ahn JS, Jung CW, Kim K, Ahn YC, Kang WK, Park K, Kim WS. The impact of Epstein-Barr virus status on clinical outcome in diffuse large B-cell lymphoma. Blood. 2007. 110: 972-978.

Petry A, Djordjevic T, Weitnauer M, Kietzmann T, Hess J, Gorlach A. NOX2 and NOX4 mediate proliferative response in endothelial cells. Antioxid Redox Signal. 2006. 8: 1473-1484.

Qi ZL, Han XQ, Hu J, Wang GH, Gao JW, Wang X, Liang DY. Comparison of three methods for the detection of EpsteinBarr virus in Hodgkin's lymphoma in paraffin-embedded tissues. Mol Med Rep. 2013. 7: 89-92.

Raab-Traub N. Epstein-Barr virus and nasopharyngeal carcinoma. Semin Cancer Biol. 1992. 3: 297-307.

Rosa MD, Gottlieb E, Lerner MR, Steitz JA. Striking similarities are exhibited by two small Epstein-Barr virus-encoded ribonucleic acids and the adenovirus-associated ribonucleic acids VAI and VAII. Mol Cell Biol. 1981. 1: 785-796.

Smith A, Howell D, Patmore R, Jack A, Roman E. Incidence of haematological malignancy by sub-type: a report from the Haematological Malignancy Research Network. Br J Cancer. 2011. 105: 1684-1692.

Smith A, Roman E, Howell D, Jones R, Patmore R, Jack A. The Haematological Malignancy Research Network (HMRN): a new information strategy for population based epidemiology and health service research. Br J Haematol. 2010. 148: 739 -753 .

The Non-Hodgkin's Lymphoma Classification Project. A clinical evaluation of the International Lymphoma Study Group classification of non-Hodgkin's lymphoma. Blood. 1997. 89: 3909-3918.

Vinay K, Abul KA, Nelson F, Jon CA. Robbins \& Cotran Pathologic Basis of Disease. 2010. 607. Saunders. Philadelphia.

Yang L, Aozasa K, Oshimi K, Takada K. Epstein-Barr virus (EBV)encoded RNA promotes growth of EBV-infected $\mathrm{T}$ cells through interleukin-9 induction. Cancer Res. 2004. 64: 5332 -5337 . 